\title{
Do rope and washer pumps provide safe water and satisfied users? A case study piloting new rural water supply technology in Rumphi District, Malawi
}

\author{
Jacob C Mkandawire', Mavuto Tembo ${ }^{2}$, Muthi Nhlema ${ }^{3}$, Joel Luhanga ${ }^{4}$ and Rochelle $\mathrm{H} \mathrm{Holm}^{5 *}$ \\ 'Department of Agri-Sciences, Mzuzu University, P/Bag 201, Mzuzu 2, Malawi and District Water Office, Rumphi District Council, Rumphi, Malawi \\ ${ }^{2}$ Centre of Excellence in Water and Sanitation, Mzuzu University, P/Bag 201, Mzuzu 2, Malawi \\ ${ }^{3}$ BaseFlow, 2nd Floor, Galaxy House, Blantyre, Malawi \\ ${ }^{4}$ Department of Forestry and Environmental Management, Mzuzu University, P/Bag 201, Mzuzu 2, Malawi \\ ${ }^{5}$ Centre of Excellence in Water and Sanitation, Mzuzu University, P/Bag 201, Mzuzu 2, Malawi
}

\begin{abstract}
Innovation is needed to develop rural water supply to support sub-Saharan Africa communities that are hard to reach. The purpose of this study was to critically review rope and washer pumps that have been installed on manually drilled boreholes in 48 communities as part of a pilot project in Rumphi District, Malawi, and which serve as a sustainable source of drinking water from both technical (water quality and functionality) and social (user satisfaction) perspectives. At each water source, an infrastructure checklist was used $(n=48) ; 10$ users were interviewed ( $n=472)$; and, if the pump had water, water quality samples were collected $(n=24)$. The results show that use of a professional driller does not guarantee a functioning rope and washer pump that produces safe water. Where the pumps were functional, most provided safe drinking water. However, only $8 \%(4 / 48)$ of pumps had good water quality, a flow rate of $>20 \mathrm{~L} / \mathrm{min}$ and a full consensus of positive satisfaction among users. Pumps are not necessarily working better or worse in more remote areas. A process of introducing and creating evaluative guidelines for new (approved) technologies for rural water supply has not been established in Malawi. Sub-Saharan African governments need to be open to innovative solutions while making sure that standards, including those for functionality, water quality, user satisfaction, private operators, and human capacity for local government regulators, are being followed to ensure safe water for rural communities.
\end{abstract}

Keywords: water, Malawi, rope and washer pump, groundwater, rural

\section{INTRODUCTION}

The Government of Malawi (2016) has approved only three handpump designs for rural water supply: (i) Afridev for deep wells at the community level, (ii) Malda for shallow water tables, and (iii) Climax, for deep water tables or institutional boreholes. The Government has been slow to respond to requests to introduce new technology, and there is no clear process for introducing or creating guidelines that evaluate new technologies for rural water supply in Malawi.

In Malawi, the operation and maintenance of rural water supply is decentralized and is covered under a community-based management model, i.e., in the hands of the user community. The user communities pay for the full costs of ongoing pump operation and maintenance, which include services from area mechanics and the purchase of spare parts in consultation with the local government and the private sector (Malawi Government, 2005; 2015). Chowns (2015) argues that, in regard to rural water supply in Malawi, this system of user management and financing of maintenance does not work well for rural communities when it is used to transfer the responsibilities of providing and maintaining public services from the local government to communities.

Recently, rope and washer pumps have been the subject of a relatively small number of studies (Fig. 1) in sub-Saharan Africa (Harvey and Drouin, 2006; Coloru et al., 2012; Butterworth et al., 2013; Holm et al., 2017). Water and public health professionals are trying to understand and manage the rural water supply for drinking water with new approaches

*Corresponding author, email: rochelle@rochelleholm.com Received 4 July 2018; accepted in revised form 2 July 2019 to supply small communities and individual families. Sutton (2017) notes that the least-served rural communities tend to be those with less than 150 people, and the lower the number of people a handpump serves, the higher per capita life cycle cost there is for the rural water supply.

When innovative rural water supply technologies are introduced in sub-Saharan Africa, they are rarely evaluated and the reasons for dis-adoption have not been documented. However, service providers and other stakeholders can learn from those reasons to make more informed decisions the next time they provide solutions for rural and low-income communities. This study builds from the earlier work of Holm et al. (2017), which examined 19 rope and washer pumps in the Rumphi District, Malawi, which are also included in our study. The purpose of this study is to reflect critically on rope and washer pumps that have been installed on manually drilled boreholes in 48 communities as part of a pilot project to provide sustainable sources of drinking water in Rumphi District, Malawi, with a focus on both technical (water quality and functionality) and social (user satisfaction) perspectives. Findings from this work will identify the issues for best practices in sub-Saharan Africa to encourage national guidelines for improving rural groundwater supply management based on the regulation of low-cost alternative technologies to ensure safe drinking water for rural communities.

\section{METHODS}

Forty-eight communities were purposely selected from Rumphi District in the Traditional Authorities, a subdivision of the district, of: Chisovya, Kachulu, Mwahenga, Mwalweni, Mwamlowe, and Mwankhunikira. These communities were 


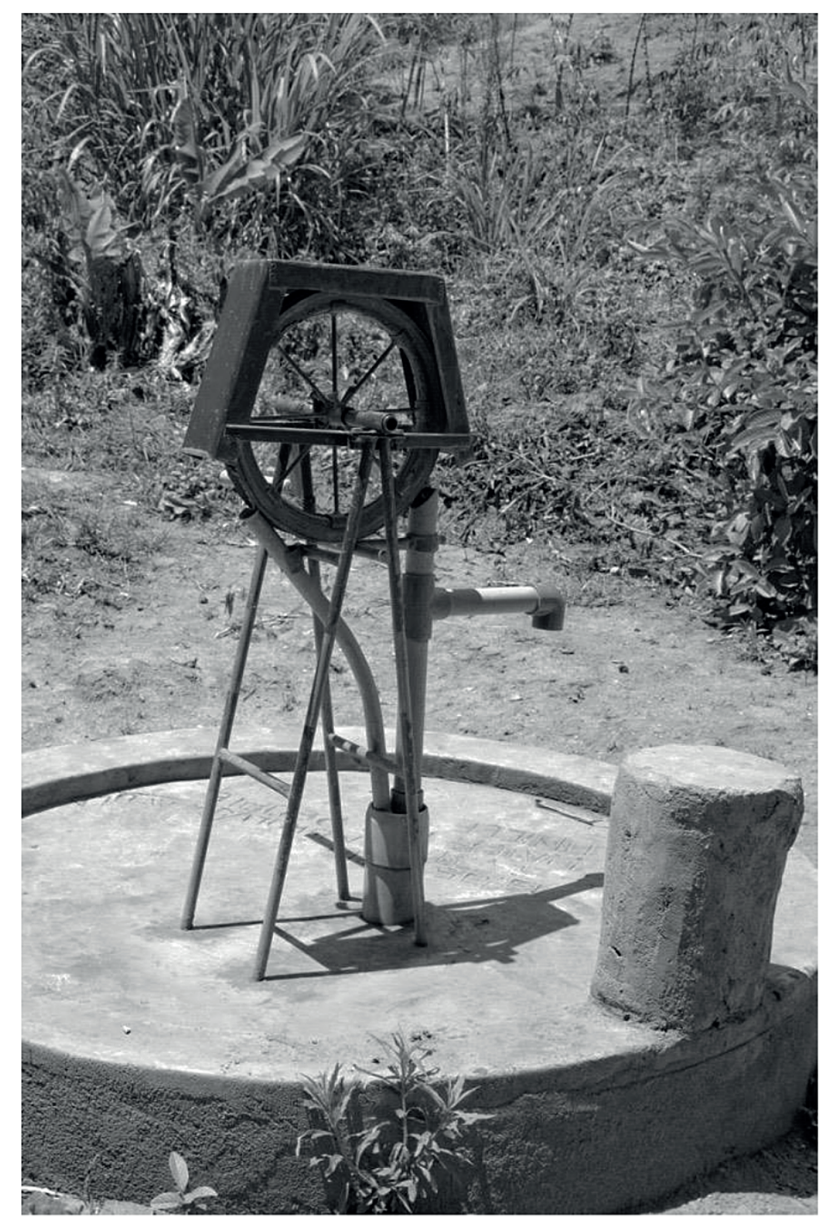

Figure 1. Rope and washer pump, Rumphi District

generally in hard-to-reach areas and had participated in the selection of the rope and washer pump for their community as the technology was introduced under a supported development partner project (Holm et al., 2017). Manually drilled wells were completed between approximately April and October 2016. The drillers reported that the depth ranged from 9.8 to $21 \mathrm{~m}$ below ground surface. The pumps were installed at each well within a few months of completion. The wells in this study were within the same geographical area and were presumed to be accessing the same aquifer.

A transformative mixed methods approach was used (Creswell, 2014). The field study was conducted during a 3-month period between December 2017 and February 2018. The first site visits were conducted in the hot season just before the first rains in December and the second visits were conducted during the wet months of January and February 2018. Each pump was visited a minimum of 2 times. At each water source, an infrastructure checklist was used, 10 users were purposely interviewed, and water quality samples were collected.

The infrastructure checklist included determining whether water was available on the day of the visit and observing the visual condition of the pump and the surrounding environment. For the user survey, there was a preference for interviewing the available female users of the study pumps; community chiefs and water point committee members were also included. All interviews were conducted by a local government representative.

The user survey included questions on recent breakdowns, maintenance, and user satisfaction (yes/no) with the pump. Survey data were collected on an android system using Open Data Kit software (Open Source, University of Washington, Seattle, Washington, USA).

When water was available at the pump, samples were analysed for thermotolerant coliforms, turbidity, $\mathrm{pH}$, total hardness, total alkalinity, free chlorine, and total chlorine. Samples for thermotolerant coliforms were collected in Whirl-Pak plastic bags (Nasco, Fort Atkinson, Wisconsin, USA) and transported to a centrally located field laboratory within Rumphi District. All thermotolerant coliform analyses were performed in duplicate within $8 \mathrm{~h}$. The Wagtech Potatest Membrane Filtration Unit (Palintest USA, Erlanger, Kentucky) was used at $44^{\circ} \mathrm{C}$ for $18 \mathrm{~h}$ for the determination of thermotolerant coliforms. One equipment blank was analysed daily to monitor for field laboratory contamination by using boiled and cooled water, and each equipment blank recorded 0 colony-forming units $(\mathrm{cfu}) / 100 \mathrm{~mL}$. An analysis of the water samples was also performed in duplicate onsite at the pump with the Wagtech Potatest Pocket $\mathrm{pH}$ Sensor (Palintest USA, Erlanger, Kentucky), Jackson turbidity tubes, and Hach Aquachek 5-in-1 Water Quality Test Strips (Hach Company, Loveland, Colorado) which were used to analyse the total hardness, total alkalinity, free chlorine, and total chlorine. The samples were not filtered.

In addition, the local government records on the well depth, the driller's name, and the pump committee chair gender were compiled. Wells that were classified as the most rural either required boats to access the community (no passable road during the field study) or were several hours of travel by road from a major trading centre.

The study covered two climatic seasons, and from the first to the second visit it was becoming wetter. Wells were classified for functionality based on the first site visit. Pumps were categorized as 'functional' if any amount of water was available at the time of the first site visit, even if the pump had problems. Nonfunctional wells were not pumping any water on the first visit. A subset of the functional wells were classified as sustainable. Sustainability with regard to this paper is defined as when the pumps had water during both the first visit before rains started and second visit during rains, safe drinking water based on thermotolerant coliforms (Malawi Bureau of Standards, 2005), all users surveyed indicated that they were satisfied with the pump, and that flow rate was at least $20 \mathrm{~L} / \mathrm{min}$.

Water quality, functionality, sustainability, and the infrastructure checklist data were analysed by using the $\mathrm{R}$ Project 3.3.2 statistical package (Vienna, Austria) at $p<0.05$. The water quality was compared to national and World Health Organization (WHO) guidelines for drinking water (Malawi Bureau of Standards, 2005; WHO, 2017).

Ethical clearance for this study was obtained from the Government of Malawi, National Commission for Science and Technology (Protocol P.10/17/221). Written consent was obtained from user respondents. All research tools and data are available from the corresponding author.

\section{RESULTS}

\section{Water quality}

The water quality from rope and washer pumps was compared with Malawi specifications for the raw groundwater that is used for drinking and WHO drinking water guidelines (Table 1) (Malawi Bureau of Standards, 2005; WHO, 2017). There were 
only 24 wells where water could be pumped at the time of water sampling during the first visit. One pump that could not be located is detailed further in the 'Study limitations' section below. Most pumps (22/24) had water that was suitable for drinking based on the local standards for thermotolerant coliforms (Malawi Bureau of Standards, 2005), yet less than half of the pumps $(11 / 24)$ provided water that is suitable for drinking based on the more stringent WHO (2017) guidelines for thermotolerant coliforms. Many pumps had clear water (e.g., $15 / 24$ pumps had turbidity at $<5$ Jackson turbidity units [JTU]).

Some wells were not necessarily sited properly, with $7 / 48$ pumps within $30 \mathrm{~m}$ of a pit latrine. Whether the pit latrine was constructed after well installation or whether this was due to initial improper siting by the driller could not be determined.

Two pumps (2/24) had high thermotolerant coliform levels ( $>200 \mathrm{cfu} / 100 \mathrm{~mL}$ ), which indicated that the water was not suitable for drinking, yet at least some (3 users) of the interviewed users of each of these two pumps indicated that the water was used by their household for drinking. Additionally, while both pumps had cloudy water, one pump was also linked to the highest turbidity (500 JTU) in this study. Each of these two pumps during the first visit had a latrine that was observed to be located higher in elevation than the pump and with an unclean site (trash or animal waste surrounding the pump). But, only one pump was within $30 \mathrm{~m}$ of a pit latrine. Both of these pumps had a surface slab that was in good condition (no cracks in the apron) and a functioning soak-away pit for excess water to be drained into. Whether sources of thermotolerant coliform contamination were already there before well installation or a result of user activities around the pump after construction could not be determined.

Free and total chlorine results were both $0 \mathrm{mg} / \mathrm{L}$ for all pumps (24/24), which indicated that none of the pumps had recently been disinfected by using sodium hypochlorite. The pH ranged from 5.9 to 7.3 , with only one pump outside of the national standard range (Malawi Bureau of Standards, 2005). The total alkalinity ranged from 40 to $180 \mathrm{mg} / \mathrm{L}$ as $\mathrm{CaCO}_{3}$, while all samples for total hardness were below the $800 \mathrm{mg} / \mathrm{L}$ $\mathrm{CaCO}_{3}$ national standard (Malawi Bureau of Standards, 2005).

\section{Functionality}

In addition to indicating a functional pump providing water, 'functionality' is also a gauge to ascertain whether the right holders who use the pump are also maintaining it. Functionality of rope and washer pumps depends on being: (i) installed properly; (ii) have an operation and maintenance system; and (iii) have a groundwater management strategy. Installation problems might include: improper alignment of the pipes and the rope, which might lead to faster wear and tear of the rope even when replaced with a new rope, the rope getting stuck in the rising main pipe, or the well not being drilled deep or straight enough. The operation and maintenance management system includes determining who is responsible and who pays for worn-out parts, which need to be affordable and available from an accessible trained pump repairer. Groundwater management strategies come down to aquifer characteristics and an appropriate number of users for a resource, because water availability is affected when the rate of abstraction is greater than the rate of groundwater recharge. During the dry season, this might lead to the water table moving below the depth of the well, which results in the lack of available water, even though the pump might not have any technical, operational or maintenance problems.

The functionality results of our study indicated that nearly half of the pumps (23/48) were non-functional (i.e., there was no water available) on the first site visit (Fig. 2). The study did not specifically observe any groundwater management or regional recharge concerns that are linked to non-functionality. While for 6 pumps, including some of the pumps that were non-functional for the longest time, non-functionality was linked to installation problems from the beginning. Yet, nonfunctionality was more likely to be linked to operation and maintenance. During the course of the study, several pumps (13/48) changed status, either changing their status from having water to not or vice versa. For those pumps that were non-functional on the first site visit, the issue was commonly attributed to the rope, such as wearing out due to friction and breaking quickly due to borehole verticality $(16 / 17)$ or the rope stuck within the pipe (but still intact) (1/17). No cases of rope theft were identified. Where there is a need for a new rope, the

Table 1. Water quality results of rope and washer pumps and comparison with Malawi and World Health Organization drinking water guidelines

\begin{tabular}{|c|c|c|c|c|c|}
\hline & \multicolumn{5}{|c|}{ Parameter } \\
\hline & $\begin{array}{l}\text { Thermotolerant coliform } \\
\text { (colony forming units } / 100 \mathrm{~mL} \text { ) }\end{array}$ & Turbidity & $\begin{array}{l}\text { Total hardness } \\
\left(\mathrm{mg} / \mathrm{L} \text { as } \mathrm{CaCO}_{3}\right)\end{array}$ & $\begin{array}{l}\text { Total alkalinity } \\
\left(\mathrm{mg} / \mathrm{L} \text { as } \mathrm{CaCO}_{3}\right)\end{array}$ & $\mathrm{pH}$ \\
\hline $\begin{array}{l}\text { Minimum } \\
(n=24)\end{array}$ & 0 & $<5 \mathrm{JTU}$ & 25 & 40 & 5.9 \\
\hline $\begin{array}{l}\text { Mean } \\
(n=24)\end{array}$ & 20 & $40 \mathrm{JTU}$ & 120 & 80 & 6.5 \\
\hline $\begin{array}{l}\text { Median } \\
(n=24)\end{array}$ & 1 & $<5$ JTU & 120 & 80 & 6.4 \\
\hline $\begin{array}{l}\text { Maximum } \\
(n=24)\end{array}$ & $>200^{c}$ & $500 \mathrm{JTU}$ & 250 & 180 & 7.3 \\
\hline Malawi Standard & 50 & 25 NTU & 800 & - & 6.0 to 9.5 \\
\hline WHO Standard ${ }^{b}$ & 0 & 1 NTU & - & - & - \\
\hline
\end{tabular}

${ }^{a}$ Malawi Bureau of Standards (MBS), 2005

${ }^{b}$ World Health Organization (WHO), 2017

${ }^{c}$ Result was too numerous to count, upper detection limit of method is reported.

${ }^{d} J T U=$ Jackson turbidity units. NTU = Nephelometric turbidity units. The two units are roughly equivalent (WHO Fact Sheet 2.33 - Turbidity

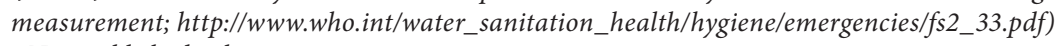

- No established value 
users would generally need to initiate the purchase of a new rope (a new rope was not observed to be kept on hand by the community), placement of washers and installation by a hired technician. The old rope would be kept by the committee. Ropes are only available to purchase at larger trading centres in the study area, not within each community. Whereas when the rope was stuck in the pipe this only required a minor adjustment by the user to put the rope in its normal position; however, until this was addressed it would result in no water flow. In Tanzania, Coloru et al. (2012) similarly found that the most common maintenance undertaken on the rope and washer pump was a replacement of the rope, as this component was most subject to wear and tear. Reasons for the non-functionality of the 23 rope and washer pumps are as shown in Table 2 .

Over half of the functional pumps (14/25) provided at least a $20 \mathrm{~L} / \mathrm{min}$ flow rate, while 3 pumps were providing $<10 \mathrm{~L} / \mathrm{min}$ of water. Most pumps (47/48) had bolts and nuts that were visually observed to be in good condition. Of the 48 study pumps, only two were observed to have both problems with the surface slab condition (such as cracks in the apron) and a non-functioning soak away pit; both these pumps were non-functional on the first site visit.

Twelve individual professionally trained drillers from within the district each installed 1 to 13 pumps of the 48 pumps. Although the sample size is small, the following trends can still be considered: 5 of the drillers had all non-functional

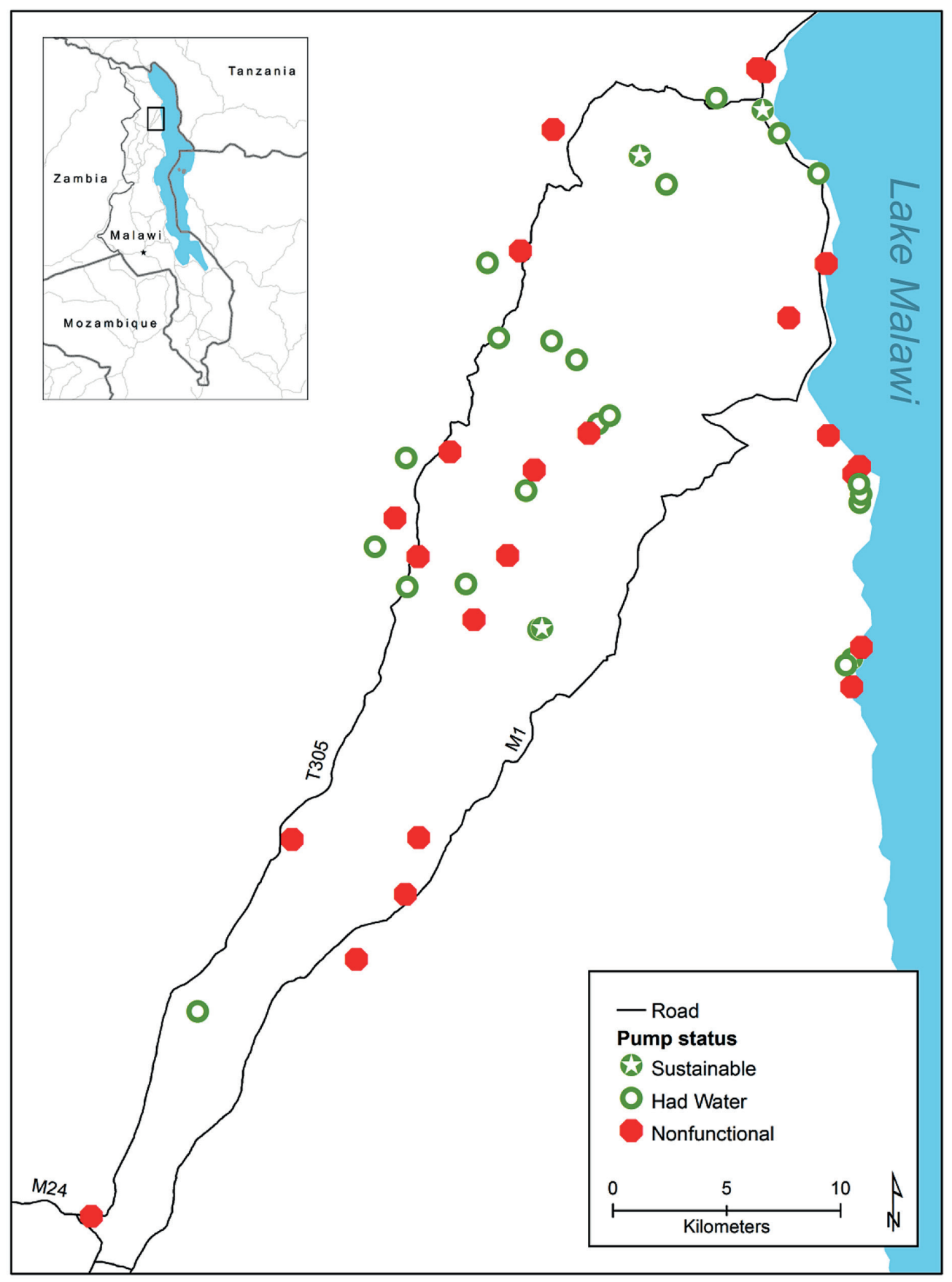

Figure 2. Map of the study area showing the pump location and status. The inset shows the study area within Rumphi District in Malawi (Africa). 
Table 2. Probable reason(s) for each pump's non-functionality $(n=23)$

\begin{tabular}{|c|c|c|c|c|}
\hline Pump ID & $\begin{array}{l}\text { Reported } \\
\text { drilled } \\
\text { depth }(\mathrm{m})\end{array}$ & $\begin{array}{l}\text { Driller } \\
\text { ID* }^{*}\end{array}$ & $\begin{array}{l}\text { How long have the } \\
\text { users reported that } \\
\text { the well has been } \\
\text { non-functional? }\end{array}$ & Probable reason(s) for each pump's non-functionality \\
\hline P1 & 14 & $J$ & 2 years & $\begin{array}{l}\text { The well was not drilled deep enough; respondents indicated low water } \\
\text { quantity. The pump has been used once since installation. }\end{array}$ \\
\hline P2 & 18.4 & $\mathrm{H}$ & $1+$ years & $\begin{array}{l}\text { The well was not drilled deep enough; respondents indicated the wel } \\
\text { produces some water during rainy season only. }\end{array}$ \\
\hline P3 & 11 & $\mathrm{~F}$ & $1+$ years & The rope is stuck in the rising main pipe. \\
\hline P4 & 19.5 & $A$ & $1+$ years & $\begin{array}{l}\text { The well was not drilled deep enough; respondents indicated low water } \\
\text { quantity. The pump has not been used since installation. }\end{array}$ \\
\hline P5 & 13.1 & B & 1 year & $\begin{array}{l}\text { Respondents indicated that there is no trained committee and that the } \\
\text { driller handed over a non-functional pump to the community. }\end{array}$ \\
\hline P6 & 11.7 & $\mathrm{C}$ & 7 months & Worn rope, there is a need for a new rope. \\
\hline P7 & 17.5 & A & $>4$ months & Worn rope, there is a need for a new rope. \\
\hline P8 & 12.6 & $\mathrm{C}$ & 4 months & $\begin{array}{l}\text { Worn rope, there is a need for a new rope. As an alternative water source } \\
\text { the community is currently getting water at the school where there is an } \\
\text { Afridev pump. }\end{array}$ \\
\hline P9 & 11 & $\mathrm{C}$ & 4 months & Worn rope, there is a need for a new rope and washers. \\
\hline P10 & 16 & $E$ & 4 months & $\begin{array}{l}\text { The well was not drilled deep enough; respondents indicated the wel } \\
\text { produces some water during rainy season only. }\end{array}$ \\
\hline P11 & 9.8 & $\mathrm{C}$ & 3 months & $\begin{array}{l}\text { There is a need for a replacing the worn rope and a new rising main pipe. The } \\
\text { community has a poorly organized committee. }\end{array}$ \\
\hline P12 & 13.5 & $\mathrm{C}$ & 2 months & The worn wheel needs to be replaced. \\
\hline P13 & 10.9 & $\mathrm{C}$ & 1 month & $\begin{array}{l}\text { Worn rope, there is a need for a new rope. The committee stated they do not } \\
\text { have money to buy the rope. }\end{array}$ \\
\hline P14 & 19.8 & I & 1 month & $\begin{array}{l}\text { Worn rope, there is a need for a new rope. The community has a poorly } \\
\text { organized committee and stated they do not have money to buy the rope }\end{array}$ \\
\hline P15 & 15.2 & $\mathrm{C}$ & 1 month & Worn rope, there is a need for a new rope. \\
\hline P16 & 12 & G & 1 month & $\begin{array}{l}\text { Worn rope, there is a need for a new rope. Otherwise the pump is in good } \\
\text { condition. }\end{array}$ \\
\hline P17 & 14.5 & $J$ & 1 month & There is a need for a new rope. \\
\hline P18 & 11.5 & $\mathrm{C}$ & 3 weeks & $\begin{array}{l}\text { Worn rope, there is a need for a new rope which the committee stated wil } \\
\text { be done soon. }\end{array}$ \\
\hline P19 & 12.8 & $\mathrm{C}$ & 2 weeks & $\begin{array}{l}\text { Worn rope, there is a need for a new rope and set of washers. As an alternative } \\
\text { water source, the community is currently getting water from the lake. }\end{array}$ \\
\hline P20 & 15 & G & 2 weeks & $\begin{array}{l}\text { Worn rope, there is a need for a new rope. Otherwise the pump is in good } \\
\text { condition. }\end{array}$ \\
\hline P21 & 12.5 & G & 2 weeks & Worn rope, there is a need for a new rope. \\
\hline P22 & 21 & D & 2 days & Worn rope, there is a need for a new rope and washers. \\
\hline P23 & 15.5 & $J$ & 1 day & $\begin{array}{l}\text { Worn rope, there is a need for a new rope and set of washers. Additionally } \\
\text { the well was possibly not drilled deep enough; the respondents indicated } \\
\text { that the well produces some water and then stops. }\end{array}$ \\
\hline
\end{tabular}

${ }^{\star}$ Driller names have been anonymized; there were 10 drillers for the 23 non-functional wells, and each was assigned a Driller ID of A to J

pumps, while 5 other drillers had a mix of functional and non-functional pumps, and only two of the drillers had each of the pumps they had installed as functional pumps. For the 5 drillers which had all non-functional pumps, each installed only 1 to 2 pumps and the probable reason(s) for non-functionality were, for 4 pumps, that it was not installed properly, whereas 2 pumps had an operation and maintenance system failure. The Kruskal-Wallis rank sum test showed that there were differences $(p=0.010)$ in the depth drilled that was reported by the driller; some drillers went deeper.

\section{User feedback}

User satisfaction may be linked to the quantity or quality of water, as well as ease of operation and operational and maintenance issues. Approximately $75 \%$ (352/472) of the respondents were satisfied with their pump and 57\% (277/472) of the users reported that after installation the rope and washer pumps had provided uninterrupted service when they needed it. However, variation in the water availability was reported by users within the same community at $32 / 48$ pumps, which possibly indicated different usage patterns or other secondary sources of water other than the rope and washer pumps being studied. When those users without uninterrupted service were asked what alternative source(s) were used when the rope and washer pump was not used or not functioning, many (148/195) reported using an unprotected water source, such as a river, lake, or open shallow well, because these were the nearest available alternatives. When pumps were providing water (functional), the users were more likely to be satisfied than those with nonfunctional pumps, based on a Fisher's Exact Test $(p<0.05)$.

Rural water supply users may judge the quality of water based on subjective indicators, such as colour, smell, taste and hardness, rather than objective water quality results. Many (414/472) users 
reported that they liked the taste of the water coming from the pump. But, if the rope and washer pump was functional, users were not always drinking water from it due to user preferences. Five respondents from two communities indicated that there was water available at their pump, but they were not drinking water from it because the water had a bad smell; however, the water was suitable for drinking based on the local standards for thermotolerant coliforms (Malawi Bureau of Standards, 2005).

For 37\% (176/472) of the users, the pumps had been broken down for more than 1 day in the last 30 days (not including outages due to routine maintenance). This user feedback also triangulates well with the researcher field observations of pumps with frequently changing status of whether it had water or not. When a pump stopped providing water, users reported that it took 1 to 6 months to repair the pump. At one non-functional pump during the first site visit researchers probed further, which was possible because when the research team arrived at the site the trained driller who lived $0.5 \mathrm{~km}$ away also came to the community. Users reported the pump had been non-functional for 1 month, though before that the community reported that the water supply was good. During onsite discussions with the community, researchers, and the trained driller, it was determined that a section of the rope needed to be replaced and the handle needed oil to bring the pump back to a functional status. Materials for the repair were not available in the community, but were available at the nearest market town. The approximate cost was MK500 (0.71 USD) for materials and an additional MK500 (0.71 USD) for labour. This is a specific example where, despite the nearby trained driller and materials for repair available at the nearest market town, uninterrupted service could not be maintained as users are responsible for at least initiating repairs. The well was subsequently fixed, and observed to be functional by researchers during the second site visit.

It is an important criterion that users should know the management structure for their water point. Water point committees are a subset of 10 community users elected for decision-making and management roles related to pump operation and maintenance, while users that are not part of the committee would typically have limited roles in water source management. Water point committees were also responsible for cleaning the water point's surroundings and providing security against vandalism. Local government records indicate that each of the 48 pumps had a committee. Many (386/472) users reported that there was a functional water point committee for their rope and washer pump. Many users (298/472) also reported that it was this committee that was responsible for the maintenance of the water point, while 125/472 users reported that it was a hired technician who performed the maintenance and was paid by the committee with user community contributions. Of the pumps studied, $27 / 48$ of these have a female committee chairperson. Women are encouraged by the local government to actively participate in decision making concerning rural water supply.

In addition to drinking water, other reported uses (186/472) included agricultural activity (gardens watered with buckets or livestock watering), brick making, and domestic uses (cooking, bathing and washing clothes). Only one community named another community within the geographic area, but outside the scope of the supported development partner project, that had a rope and washer pump installed at a small hotel offering accommodation for travellers and categorized it as being for commercial purposes.

Less than half of the users (181/472) reported that there were cash resources that have been collected as user fees for the pump's operation and maintenance, and only 6\% (30/472) knew how much a rope and washer pump costs. If given an opportunity to choose amongst the technologies that would work in their community, approximately one quarter (130/472) would still choose the rope and washer pump. This also compares to an approximately equal number of users (116/472) who indicated that, if given the opportunity to choose what might work well in their community, they would want a piped water supply.

\section{Sustainability}

Following the infrastructure checklist, user interviews, and water quality analysis, an assessment was made by researchers of the pumps' technical, operational or maintenance sustainability based on 4 checks: that it was providing water, water was safe for drinking based on thermotolerant coliforms (Malawi Bureau of Standards, 2005), all the users surveyed for that pump indicated that the individuals expressed satisfaction with the pump, and there was a flow rate of at least $20 \mathrm{~L} / \mathrm{min}$. The results suggest that rope and washer pumps were working as a sustainable rural water supply in $8 \%(4 / 48)$ of communities.

Of the 8 pumps classified as the most rural, only one of these qualified as being sustainable by our study criteria. To determine if there was a variation between the remoteness of the pump and the three pump status groups (is non-functional, had water, and is sustainable), Fisher's Exact Test showed no differences $(p=0.86)$. This indicates that the pumps are not necessarily working better or worse in more remote areas. To determine if there is a variation between the gender of the water committee chair and the three pump status groups (is non-functional, had water, and is sustainable), a Fisher's Exact Test showed no differences $(p=0.56)$. This means that a female committee leader did not necessarily lead to a more, or less, sustainable rope and washer pump. Also, the Kruskal-Wallis rank sum test further showed that deeper wells were not necessarily more likely to be sustainable $(p=0.53)$. The Fisher Exact Test relation between whether a specific driller was more likely to have a sustainable ranking showed no differences $(p=0.54)$.

In addition, the monitoring logistics of rural pumps for sustainability is expensive. This current study cost approximately 3000 USD for the 48 pumps.

\section{DISCUSSION}

A rigorous examination of the elements of water quality, infrastructure, and user feedback might help to spread sustainable rural water supply practices. Where the rope and washer pumps were functional, for most the water quality met national guidelines. Yet, pumps were working sustainably as sources of rural water supply in only 4 of 48 study communities.

A professional driller did not guarantee a sustainable rural water supply. For at least some of the non-functional wells there is an indication that pumps may have been impacted by high failure rates soon after installation. In addition, some of the water sources may need to be drilled deeper. Yet, the aim to have water users and private operators completely independent of government regulation by using a low-cost technology was also not being completely met over the longer term, as observed in this study. It could be that the private operators, although having been trained and being geographically available to customers, may not have been profitable, able to be reached by users, or there may have been too many operators 
within the study area. Thus, there may have been too much competition among private operators or poor communication with users within the start-up period, but this needs further investigation. The functionality of rope and washer pumps had great variability, but could be a cycle in which quality control is more difficult when local regulations are not in place for a new technology. However, the functionality of the rope and washer pumps in this study was even lower than the rates reported for Elephant pumps in rural Malawi, which are a similar covered rope and washer pump design and also not approved by the Malawi Government (Holm et al., 2015). More widely, the functionality of water points (inclusive of handpumps, piped water, and unimproved sources) in Malawi is reported to be 79\% (Banks and Furey, 2016), in which case the pumps under study had a lower overall functionality than this average.

In the approximately 2 years from drilling completion to the time of our study, there was a slow scale-up of the low-cost technology for surrounding geographic areas for household or community utilization, for which private individuals may have paid the full cost to the trained drillers. Users who are happy with the rope and washer pump did not necessarily share this information outside their community, nor are they excited enough about rope and washer pumps to further install their own rope and washer pump at home. One of the factors that affects user satisfaction is the ease of the pumping motion by the user, which is a function of the depth of the well and maintenance, although this needs further research over time, both as the pump is used more and as it gets older. Although someone must take the lead to promote a new technology, the low adoption rate is likely a result of the non-functionality of rope and washer pumps in the study area, and that the communities that were targeted with the rope and washer pumps were small and isolated.

In view of the rural water supply model that is currently operating in Malawi and which depends on decentralized management (Malawi Government, 2005), one aspect that ensures that rural water supplies are sustainable is the ability of these communities to take care of their own supplies. The aspect of ownership ultimately rests with the community, which must be empowered and not wait for Government or outside agencies to repair and maintain supplies. There is a disconnect between pump users knowing that there is a water point committee and local government reporting that each of the 48 pumps had a committee. Our research is also consistent with findings of Chowns (2015), who found that the community management of rural water supply in Malawi does not work, because maintenance is not performed and water point committees are unable to manage funds. A specific example of this in our study is the high rate of pumps for which it was needed to replace or tighten the rope.

The wells under this study are, in general, strictly rural water supply systems. In some cases, the research team had to hike or take a boat to access the water sources, as neither a motorcycle nor a $4 \times 4$ vehicle could reach the sites. These hardest to reach areas are inaccessible to conventional drilling rigs. Of the 8 most rural pumps, only one was classified as sustainable, yet this is where rope and washer pumps with manual drilling have been marketed to have the most impact. Access to spare parts and access to information in these hardest to reach areas likely plays a role and needs further detailed study.

In Ethiopia, rope and washer pumps are being installed for joint irrigation and domestic use (Butterworth et al., 2013). The pumps in this study were used for both drinking and nondrinking water purposes, although possibly not as strongly as in Ethiopia for multiple-use water services. In Ethiopia, many of the farmers using rope and washer pumps wanted to change their water lifting technologies (Nigussie et al., 2017). However, when the pumps in this study were providing water, users were generally satisfied.

The rising main on rope and water pumps is polyvinyl chloride (PVC); the quality of water is, therefore, site specific, and contamination may come from sources at, around, and near the water source and may not necessarily be related to the type of pump, assuming the pump is properly installed. In terms of safe water, the pumps in our study generally had better water quality than reported results for rope and washer pumps in other countries (Harvey and Drouin, 2006; Bennett et al., 2010; Coloru et al., 2012; Butterworth et al., 2013). However, there is limited drinking water quality data from Rumphi District (Holm et al., 2018) for the three Government of Malawi (2016) approved handpump designs. In the case where the pump is not being used for drinking water, the national and WHO guidelines used in our evaluation would not apply. This study has shown that, despite having a pump that is not fully enclosed, safe water can be provided effectively by rope and washer pumps.

Hutchings (2018) argues that management of rural water supply relies heavily on state supporting agencies. The Government of Malawi (2016) technical manual specifically outlines three approved handpump designs and leaves no room for the assessment criteria of alternative rural water supply technology. In addition, the community-based management training manual (Malawi Government, 2015) is equally specific and only covers Afridev pumps. In the case of the study pumps, the District Council was the regulator of this low-cost technology pilot project and reported to the national government. There is a need for a community-based management training manual that allows for alternative rural water supply technologies that may work in some areas, as well as supervision courses for regulators. In addition, there is an ongoing need to identifying causes of failure that stakeholders can target to improve user satisfaction, operation and maintenance.

\section{Limitations}

The study was limited to one district. Although it included all pumps that were installed as a cohort development project, this is still a small sample size. The water quality evaluation was conducted only once during the dry season, and one functional pump was skipped because it initially could not be found, although it was located later in the study. Borehole forensics, such as borehole verticality and aquifer hydraulic properties, were not conducted on non-functional wells. There may have been a conflict of interest, as the lead researcher (JM) at the time of the study was working for the Government of Malawi as the Rumphi District Water Officer managing the rural water supply. This research was not necessarily an assessment of rope and washer pumps for self-supply and, hence, did not cover financing by the user. The sustainability of groundwater resources for future use or year-round water supply was not studied, as each pump was only visited twice by researchers, though this set of rope and washer pumps had a well-documented history by Mzuzu University.

\section{CONCLUSIONS}

Most rope and washer pumps in the study, although not approved by the Government of Malawi, provided safe drinking water when working. The high non-functionality rate can be attributed 
to community management and operational or maintenance problems. Only $8 \%(4 / 48)$ of pumps had water flowing at two researcher field visits, good water quality, a flow of $>20 \mathrm{~L} / \mathrm{min}$ and full consensus of positive satisfaction among users. An approach to evaluate and introduce new technologies for rural water supplies that have not yet been approved by the national government has not been established in Malawi. However, there needs to be a balance so that practitioners may obtain data showing that an alternative rural water supply technology is working. Sub-Saharan African governments need to be open to innovative solutions while ensuring that standards, including standards for functionality, water quality, user satisfaction, private operators, and human capacity for local government regulators, are being followed to ensure safe water for rural communities.

\section{ACKNOWLEDGEMENTS}

This research has been supported as part of the Climate Justice Water Futures Programme funded by the Scottish Government and facilitated by University of Strathclyde in partnership with BASEflow through a mini-research grant. The authors appreciate the valuable feedback of Dr Kip McGilliard on a draft of this manuscript.

\section{REFERENCES}

BANKS B and FUREY SG (2016) What's working, where, and for how long. A 2016 water point update to the RWSN (2009) statistics. In Proceedings of the 7th RWSN Forum, 29 November 2016, Abidjan, Côte d'Ivoire.

BENNETT HB, SHANTZ A, SHIN G, SAMPSON ML and MESCHKE JS (2010) Characterisation of the water quality from open and ropepump shallow wells in rural Cambodia. Water Sci. Technol. 61 (2) 473-479. https://doi.org/10.2166/wst.2010.817

BUTTERWORTH J, SUTTON S and MEKONTA L (2013) Self-supply as a complementary water services delivery model in Ethiopia. Water Alternatives 6 (3) 405-423.

CHOWNS E (2015) Is community management an efficient and effective model of public service delivery? Lessons from the rural water supply sector in Malawi. Public Admin. Dev. 35 (4) 263-276. https://doi.org/10.1002/pad.1737

COLORU B, MGAYA S and TAUBERT RP (2012) Appropriate technologies for rural water supply: A comparative study between "Rope pumps" and conventional piston pumps on water quality and other sustainability parameters. Fondazione ACRA-CCS, Njombe.

CRESWELL JW (2014) Research Design: Qualitative, Quantitative, and Mixed Methods Approaches. Sage Publications, Inc., Los Angeles.
GOVERNMENT OF MALAWI (2016) Technical Manual - Water Wells and Groundwater Monitoring Systems. Ministry of Agriculture, Irrigation and Water Development, Lilongwe.

HARVEY PA and DROUIN T (2006) The case for the rope-pump in Africa: A comparative performance analysis. J. Water Health 04.4 499-510. https://doi.org/10.2166/wh.2006.0033

HOLM R, KAMANGIRA A, KASULO V, KAPONDA P, HARA E, CARNEY-FILMORE C and NHLEMA M (2017) The handpump choice is yours: A pilot study in Rumphi District, Malawi. Waterlines 36 (4) 358-366. https://doi. org/10.3362/1756-3488.17-00006

HOLM R, STROUD R, MSILIMBA G and GWAYI S (2015) Functionality and water quality of Elephant pumps: Implications for sustainable drinking water supplies in rural Malawi. Groundwater Sustainable Dev. 1 129-134. https://doi.org/10.1016/j. gsd.2016.02.001

HOLM RH, KUNKEL G and NYIRENDA L (2018) A thought leadership piece: Where are the rural groundwater quality data for the assessment of health risks in northern Malawi? Groundwater Sustainable Dev. 7 157-163. https://doi.org/10.1016/j. gsd.2018.05.004

HUTCHINGS P (2018) Community management or coproduction? The role of state and citizens in rural water service delivery in India. Water Alternatives 11 (2) 357-374.

MALAWI BUREAU OF STANDARDS (MBS) (2005) Malawi standard; Borehole and shallow well water quality- specification, MS 733:2005. Malawi Standards Board, Blantyre, Malawi.

MALAWI GOVERNMENT (2005) National water policy. Malawi Government, Lilongwe.

MALAWI GOVERNMENT (2015) Rural Water Supply Operation and Maintenance Series 1 - Community Based Management (O \& M Refresher Course) Training Manual. Ministry of Agriculture, Irrigation and Water Development (MoAIWD). Malawi Government, Lilongwe.

MALAWI GOVERNMENT (2016) Technical Manual - Water Wells and Groundwater Monitoring Systems. Ministry of Agriculture, Irrigation and Water Development. Malawi Government, Lilongwe.

NIGUSSIE L, LEFORE N, SCHMITTER P and NICOL A (2017) Gender and water technologies: Water lifting for irrigation and multiple purposes in Ethiopia. International Water Management Institute, East Africa and Nile Basin Office, Addis Ababa.

SUTTON S (2017) Trends in sub-Saharan rural water supply and the essential inclusion of self-supply to achieve 2030 SDG targets. Waterlines 36 (4) 339-357. https://doi. org/10.3362/1756-3488.17-00013

WORLD HEALTH ORGANIZATION (WHO) (2017) Guidelines for Drinking-water Quality, Fourth Edition Incorporating the First Addendum. URL:http://apps.who.int/iris/bitstream/han dle/10665/254637/9789241549950-eng.pdf;jsessionid=054D53AD5E E1CCD6C897ED3194E1EB80? sequence=1(Accessed 22 April 2018). 